\title{
PRESENTACIÓN: REGIONALISMO VERSUS CENTRALISMO: LA FORMACIÓN DEL ESTADO EN CHILE (1810-1850)
}

\section{Regionalism versus centralism: Statebuilding in Chile (1810-1850)}

\author{
Elvira López Taverne \\ Pontificia Universidad Católica de Chile \\ eelopez@uc.cl \\ Joaquín Fernández Abara \\ Universidad Finis Terrae (Santigo de Chile) \\ jfernandez@uft.cl
}

El modelo de construcción estatal chileno ha sido considerado por la historiografía un ejemplo para la región, por su transición más temprana y relativamente más pacífica del régimen colonial al republicano y por la consolidación de un modelo político centralizado. Según esta visión, se trataría de una forma particular respecto al camino que tomaron el resto de las repúblicas latinoamericanas tras la independencia de la monarquía española, en las que se habría experimentado de manera reiterada con diversos tipos de diseño estatal, tales como confederaciones y repúblicas federales. ${ }^{1}$

La lectura de la «excepcionalidad chilena» que hicieron intelectuales como Juan Bautista Alberdi ${ }^{2}$ fue ampliamente difundida por los historiadores liberales chilenos del siglo XIX, como Diego Barros Arana, los hermanos Amunátegui y Benjamín Vicuña Mackenna, y ha tendido a ser replicada, en términos generales, en el análisis historiográfico latinoamericanista, sin haber sido suficientemente problematizada con posterioridad. Así, algunas miradas aportadas desde historias generales de América Latina han resaltado la rapidez y «éxito» del proceso de construcción estatal chileno. Un ejemplo está presen-

1. Cf. Carmagnani, Marcello (comp.), Federalismos latinoamericanos, México-Buenos Aires, Fondo de Cultura Económica, 1994; Bragoni, Beatriz y Eduardo Míguez (comps.), Un nuevo orden político. Provincias y Estado Nacional, 1852-1880, Buenos Aires, Editorial Biblos, 2010.

2. Alberdi, Juan Bautista, Bases y puntos de partida para la organización política de la República de Argenti$n a$, [texto editado por Francisco Cruz], Buenos Aires, La cultura argentina, 1915. En referencia a los relatos excepcionalistas sobre la historia chilena, véase Blumenthal, Edward, El mito de la excepcionalidad chilena: un proyecto de construcción identitaria. Tesis para optar al grado de Licenciado en Historia. Santiago, Instituto de Historia de la Pontificia Universidad Católica de Chile, 2004. 
te en la obra de Tulio Halperín. Tras realizar narraciones de casos como el mexicano y rioplatense, las que superan más de tres veces en extensión al tratamiento que da al caso chileno, Halperín sostiene que «en la primera mitad del siglo XIX el éxito más considerable de la Hispanoamérica independiente» fue «el de la república conservadora de Chile». ${ }^{3}$

La recién mencionada visión se basa en una metodología que podríamos llamar de «comparación asimétrica»: un análisis en el cual una investigación más exhaustiva de casos conflictivos es comparada con una descripción menos investigada del caso «exitoso». ${ }^{4}$ Existen elementos importantes a tomar en cuenta de esta visión, dado el alcance, la duración y la intensidad que tuvieron las guerras civiles del período postindependentista en diversos escenarios hispanoamericanos, especialmente en el rioplatense. ${ }^{5}$ Sin embargo, dicha perspectiva influye en que el investigador minimice los problemas y complejidades derivados de la construcción del Estado en Chile.

En este sentido, uno de los principales aportes de la historia regional es cuestionar dicho modelo, mostrar que el proceso de formación estatal comportó oposición y desajustes, que el poder de decisión y la acción del gobierno se hacían muy débiles cuando se alejaban del centro, y que la negociación con los actores locales jugó un papel fundamental.

Paradójicamente, ciertas características que han permanecido en la historiografía regional chilena han reforzado estas tendencias, actuando en detrimento de la valoración de la importancia regional en los procesos de construcción estatal. Si bien es cierto que en Chile existe una larga tradición de historia regional, podemos decir que en muchos casos ha tendido a primar una lógica patrimonial, en cuanto reafirmación identitaria a través de la puesta en valor de elementos significativos para la memoria local. ${ }^{6}$ Dicha lógica, efectivamente, ha apuntado a relevar un aspecto importante de la vida comunitaria, aunque no siempre ha existido tras ella un afán analítico. Por ello consideramos que el

3. Halperín Donghi, Tulio, Historia contemporánea de América Latina, Madrid, Alianza Editorial, 1972, p. 204.

4. Kocka, Jurgen y Heinz-Gerhard Haupt, «Comparison and Beyond. Tradition, Scope, and Perspectives of Comparative History», en Kocka, Jurgen y Heinz-Gerhard Haupt (eds.), Comparative and Transnational History. Central European Approaches and New Perspectives, New York-Oxford, Berghahn Books, 2012, pp. 5-6.

5. La intensidad de los conflictos civiles en el ámbito rioplatense quedan en evidencia al conocer algunas cifras que ha entregado en sus investigaciones Alejandro Rabinovich, quien ha señalado que para el período postindependentista en el Río de la plata «la tasa de militarización» efectiva de la población masculina adulta», entendiendo a esta cómo el porcentaje de hombres adultos «dedicados al servicio de armas», «fue altísima, por lo menos para el período de las guerras de la revolución, solo comparable a la de Prusia en vísperas de la Revolución Francesa». Al respecto véase Rabinovich, Alejandro, «De la historia militar a la historia de la guerra. Aportes y propuestas para el estudio de la guerra en los márgenes», en Corpus. Archivos virtuales de la alteridad americana [en línea], vol. 5, n. ${ }^{\circ}$ 1, Mendoza, 2015, Publicado el 29 junio 2015, consultado el 11 julio 2018. URL: <http://journals.openedition.org/corpusarchivos/1397> y Rabinovich, Alejandro, «La militarización del Río de la Plata, 1810-1820: Elementos cuantitativos y conceptuales para un análisis», en Boletín del Instituto de Historia Argentina y Americana Dr. Emilio Ravignani, n. ${ }^{\circ}$ 37, Buenos Aires, 2012, pp. 11-42.

6. En esta línea, un análisis de los apartados sobre historia regional presentes en los balances sobre historiografía chilena realizados por Cristian Gazmuri son esclarecedores sobre las preocupaciones de dicha rama de la disciplina en Chile. Véase Gazmuri Riveros, Cristián, La Historiografía Chilena (1842-1970), tomos I y II, Santiago, Taurus, Centro de Investigaciones Diego Barros Arana, 2006-2009. 
estudio de la historia desde las regiones puede permitirnos esclarecer procesos y entender en su complejidad procesos mayores. Recientemente, algunos historiadores han comenzado a desarrollar trabajos en esta línea, dando cuenta del rol de las provincias en los procesos de independencia política y construcción estatal temprana. ${ }^{7}$

Siguiendo esta línea, el dossier que presentamos se propone justamente cuestionar y analizar la implementación de este modelo estatal fuertemente centralizado, ${ }^{8}$ característico de la organización republicana en Chile. En efecto, desde una perspectiva histórica de larga duración, la imposición del modelo centralista redundó en un afianzamiento del Estado, ${ }^{9}$ pero este proceso fue impugnado en el ámbito político y social (dos guerras civiles en una década y numerosos levantamientos y motines populares), y generó fuertes resistencias locales, particularmente en las provincias del norte y del sur, como lo demuestran las guerras civiles de 1851 y 1859 , cuando las provincias se levantaron en armas contra el gobierno central. ${ }^{10}$

La propuesta que planteamos implica necesariamente analizar desde una perspectiva histórica la noción de Estado, y ponerla en diálogo con algunos debates teóricos sobre su naturaleza. ${ }^{11}$ En primer lugar, nos obliga a no asociar automáticamente las formas estatales que estudiamos con organizaciones burocráticas modernas de tipo impersonal. Debemos atender que cuando Max Weber generó una definición de «burocracia», realizó dicha descripción en cuanto «tipo ideal»; es decir un instrumento analítico que pretende reflejar las características que definirían el estilo de administración pública moderna que ha tendido a afianzarse en el mundo occidental. ${ }^{12}$ Sin embargo, diversos autores coinciden en que dichas condiciones no siempre lograron imponerse con éxito. El propio Reinhardt Bendix, autor fuertemente influenciado por el pensamiento weberiano, ha llegado a sostener que los procesos de burocratización han tenido resultados divergentes. De hecho, a su juicio, estos podrían concebirse como la «multifacética, creciente y más o menos exitosa imposición de estas condiciones de empleo a partir del siglo XIX». ${ }^{13}$

7. Cartes Montory, Armando, Concepción contra Chile. Consensos y tensiones regionales en la Patria Vieja (1808-1811), Santiago, Centro de Estudios Bicentenario, 2010 y Cartes Montory, Armando, «Un gobierno de los pueblos...» Relaciones provinciales en la Independencia de Chile, Valparaíso, Ediciones Universitarias de Valparaíso, 2014.

8. Collier, Simon, Chile. La construcción de una república, 1830-1865, Santiago, Ediciones Universidad Católica de Chile, 2008; Salazar, Gabriel, Construcción de Estado en Chile (1800-1837). Democracia de los «pueblos». Militarismo ciudadano: Golpismo oligárquico, Santiago, Editorial Sudamericana, 2006.

9. El tema ha sido abordado en López Taverne, Elvira, El proceso de construcción estatal en Cbile. Hacienda Pública y burocracia (1817-1860), Santiago, Centro de Investigaciones Diego Barros Arana, 2013.

10. Consultar Fernández Abara, Joaquín, Regionalismo, liberalismo y rebelión. Copiapó en la guerra civil de 1859, Santiago, RIL Editores, Escuela de Historia de la Universidad Finis Terrae, 2016.

11. Estudios recientes también se plantean la necesidad de preguntarse por qué emergieron proyectos de construcción estatal en algunos países y mientras que en otros no. Al respecto véase Soifer, Hillel David, State Building in Latin América, New York, Cambridge University Press, 2015.

12. Weber, Max, Economía y Sociedad, Tomo II, México, Fondo de Cultura Económica, 1964, pp. 716 718.

13. Bendix, Reinhard, Estado nacional y ciudadanía, Buenos Aires, Amorrortu Editores, 1974, pp. 108109. 
En segundo lugar, debemos considerar que cuando analizamos procesos de crecimiento del «poder infraestructural del Estado», como el que tiene lugar en el período estudiado, hay que tener en cuenta las prevenciones que han planteado autores como Michael Mann. Esta visión muestra al poder infraestructural del Estado como una «vía de doble dirección», en la que el Estado aumenta su penetración territorial, al mismo tiempo que los «partidos» de la «sociedad civil» pueden ver incrementadas sus posibilidades de controlarlo. Esta situación resulta más clara cuando constatamos que los agentes encargados de llevar adelante este despliegue estatal pocas veces fueron cuadros burocráticos, en el estricto sentido del término. ${ }^{14}$ Según Mann, «la acción del Estado casi nunca conforma un conjunto burocrático». Si bien el «conjunto de instituciones» que compone el Estado se caracterizan por su «centralidad», «en el sentido de que las relaciones de poder irradian desde el centro y hacia el centro», las instituciones que lo componen pueden actuar con diversos grados de autonomía y ser presionados desde la sociedad civil. ${ }^{15}$

Muchos de estos problemas pueden observarse en el primer medio siglo de vida republicana en Chile. Desde tiempos coloniales el territorio chileno se había dividido en tres regiones geográfico-históricas: Coquimbo (norte), Santiago (centro) y Concepción (sur); con excepción de Santiago, el norte y el sur habían propugnado siempre en pos de un régimen descentralizado. ${ }^{16}$ En la década de 1820 ambas regiones apoyaron propuestas políticas que seguían esta línea. Tras el triunfo de los conservadores en la guerra civil de 1829 se instauró un sistema político y administrativo fuertemente autoritario, jerarquizado y centralizado, a cuya cabeza «reinaba» el presidente de la República. El jefe del Ejecutivo controlaba la administración de todo el territorio nacional, a través del nombramiento y control sobre los funcionarios administrativos, y tenía a su cargo las finanzas públicas. Esta organización de la gestión territorial tuvo como resultado una fuerte intervención electoral en las provincias, lo que redundó en un dominio del Congreso. Si a esto sumamos el control de los recursos locales y las atribuciones que la Constitución de 1833 otorgó al Presidente, resulta evidente que el modelo centralista buscaba imponerse con vigor, sin contemplaciones.

Sin embargo, diversos estudios han matizado esta imagen. Así, autores como J. Samuel Valenzuela han señalado los importantes márgenes de maniobra política que conservaron la élites locales, que obligaron al Ejecutivo a negociar con ellas. ${ }^{17}$ De un modo similar, podemos plantear que las guerras civiles de 1851 y 1859 pusieron en evidencia que el

14. Para el caso latinoamericano véase Pro Ruiz, Juan, «Considering the State from the Perspective of Bureaucracy: Lessons from the Latin American Sattelzeit», en Garavaglia, Juan Carlos y Juan Pro Ruiz (eds.), Latin American Bureaucracy and the State Building Process (1780-1860), Newcastel upon Tyne, Cambridge Scholars Publishing, 2013, pp. 1-23.

15. Mann, Michael, Las fuentes del poder social. Tomo II. El desarrollo de las clases y los estados nacionales, 1760-1914, Madrid, Alianza Editorial, 1991, pp. 90 y 92.

16. Illanes, María Angélica, Chile Des-centrado. Formación socio-cultural republicana y transición capitalista (1810-1910), Santiago, Lom Ediciones, 2003; Cartes, Armando, Concepción contra «Chile»..., cit.

17. Valenzuela, J. Samuel, «Hacia la formación de instituciones democráticas: Prácticas electorales en Chile durante el siglo XIX», Estudios Públicos, n. ${ }^{\circ}$ 58, Santiago, 1995. 
equilibrio que parecía haberse encontrado entre el centro y las provincias era precario. En efecto, en los 30 años del período comprendido entre 1829 y 1859 hubo tres guerras civiles con un contenido fuertemente regionalista, en las que diversas provincias y ciudades se manifestaron en rebeldía contra el «gobierno de Santiago», declararon «roto el pacto social», nombraron sus propias autoridades, generaron fuerzas armadas y monedas propias e incluso llegaron a establecer pactos de defensa y no agresión entre ellas. Por lo demás, si bien diversas obras historiográficas han hablado del carácter centralista del orden impuesto con el advenimiento del peluconismo, tras la guerra civil de 1829-30, prácticamente, no se ha problematizado el tipo de Estado ni el modelo de centralización que se construyó. Estudiar las tensiones que subyacían a estos conflictos se vuelve fundamental.

En efecto, durante este período, algunas características propias de un proceso de burocratización son innegables. Esta situación no era nueva, por el contrario refleja una continuidad y un reforzamiento de las pautas administrativas del período tardocolonial originadas en el reformismo borbónico. ${ }^{18}$ Así, hubo una clara tendencia a definir derechos y obligaciones de los cargos, que quedaron codificados en cuerpos legales. Esta nueva legislación tendió a establecer con mayor claridad las relaciones de autoridad y, hasta cierto punto, a formalizar las relaciones laborales entre el Estado y quienes detentaban los cargos. ${ }^{19}$ No obstante, muchas prácticas administrativas siguieron normándose por la costumbre. Por lo demás, la separación entre el cargo y su titular se vuelve difusa e irregular en el período. Esto se debía a la práctica recurrente de hacer descansar los cargos en notables o instituciones corporativas locales, hecho que se hacía cada vez más evidente a medida que se descendía en el escalafón, y se acrecentaba con la lejanía de Santiago. Por lo demás, parte importante de los cargos eran honoríficos y no contaban con remuneraciones, $y$, por lo mismo, la tarea administrativa no era asumida como una labor exclusiva por los tenedores de los cargos.

Sobre el Estado chileno se ha escrito mucho. A lo largo de los siglos XIX y XX numerosos intelectuales abordaron el tema desde perspectivas disciplinarias y tendencias políticas muy variadas. Sin embargo, primó en ellas un enfoque descriptivo de las gestas y de los prohombres que «encarnaron» el Estado más que una reflexión de fondo sobre su naturaleza y proceso de formación. De hecho, el estudio del funcionamiento de las instituciones, de las prácticas políticas y administrativas y de los cuadros burocráticos, quedó relegado a un segundo plano. ${ }^{20} \mathrm{~A}$ pesar de la diversidad de posturas, muchos autores coinciden en señalar el carácter dominante de la presencia estatal en el proceso de forma-

18. La continuidad entre las pautas administrativas del reformismo borbónico y las del nuevo orden republicano han sido tratadas para el caso mexicano por Guerrero Orozco, Omar, Las raíces borbónicas del Estado Mexicano, México D. F., Universidad Nacional Autónoma de México, 1994.

19. Nos referimos principalmente a la Constitución de 1833, la ley de Ministerios de 1837, la Ley de Régimen Interior de 1844 y la Ley de Municipalidades de 1854. Una completa cronología de estas medidas puede ser encontrada en Bravo Lira, Bernardino, Historia de las instituciones políticas de Chile e Hispanoamérica, Santiago, Editorial Andrés Bello, 1986, p. 198.

20. Véase, Sagredo, Rafael, «Élites chilenas del siglo XIX. Historiografía», Cuadernos de Historia, n. ${ }^{\circ}$ 16, Santiago, diciembre de 1996, pp. 103-132. 
ción de la nación, ${ }^{21}$ y en el peso que tuvo la institucionalidad en la construcción de la sociedad chilena. ${ }^{22}$

Ahora bien, la reflexión sobre el Estado ha privilegiado una envergadura nacional, e incluso los estudios sobre el rol de la ciudadanía y la sociedad civil en la construcción del mismo $^{23}$ han optado por esta escala. ${ }^{24}$ Es por ello que la novedad de esta propuesta son artículos que combinan la mirada global con el estudio de la formación estatal desde una escala local (estudios de caso provinciales).

En los últimos años, justamente, la historiografía chilena ha reposicionado la historia regional, poniendo énfasis en la importancia de relacionar las distintas escalas en que se desarrollan los procesos sociales y culturales. Entre los autores más reconocidos de esta tendencia se encuentran Mateo Martinic, Jorge Hidalgo, Jorge Pinto, Lautaro Nuñez y Leonardo Mazzei. Sin embargo, la formación del Estado se ha abordado siempre a nivel nacional, dadas las características intrínsecas que comporta este objeto, y dado que la estructura, instituciones y territorio que reivindica apuntan a una escala vasta.

Cabe señalar que algunas investigaciones recientes se han centrado en el análisis de la formación y funcionamiento de cuadros burocráticos, teniendo en cuenta sus redes y prácticas, ayudando a matizar la noción de un estado poderoso, altamente centralizado y efectivo que ha predominado en la historiografía chilena..$^{25}$ Por lo demás, los conflictos derivados de los procesos de burocratización y de la eventual autonomización del aparato estatal han recibido la atención de novedosos estudios en los últimos años. ${ }^{26}$

Así, con el objetivo de cuestionar esta idea de centralización que aparece como natural, que no se pregunta por la diversidad de los tiempos, las resistencias que genera, las distintas escalas en que opera, ni los intereses locales que conlleva, optamos por posicionarnos desde lo regional, no solo como escala de observación, sino como aproximación teórica para pensar el Estado.

21. Góngora, Mario, Ensayo bistórico sobre la noción de Estado en Chile en los siglos XIX y XX, Santiago, La Ciudad, 1981; Eyzaguirre, Jaime, Historia de las instituciones políticas y sociales de Chile, Santiago, Editorial Universitaria, 1967; y Jocelyn-Holt, Alfredo, La independencia de Chile. Tradición, modernización y mito, Madrid, Mapfre, 1992 y El peso de la noche: nuestra frágil fortaleza histórica, Buenos Aires, Editorial Planeta, 1997.

22. Salazar, Gabriel y Julio Pinto, Historia contemporánea de Chile, Santiago, Lom Ediciones, vol. I, 1999.

23. Pinto, Julio y Verónica Valdivia, ¿Chilenos todos? La construcción social de la nación (1810-1840), Santiago, Lom Ediciones, 2009; y Pinto, Julio, «¿La tendencia de la masa al reposo? El régimen portaliano enfrenta al mundo plebeyo, 1830-1851», Historia, n. ${ }^{\circ} 44$, vol. II, Santiago, julio-diciembre de 2011, pp. 401-442.

24. La excepción serían los estudios sobre comunidades marginadas al proceso de construcción estatal, como las indígenas. Véase, Pinto, Jorge, La formación del Estado y la nación y el pueblo Mapuche. De la inclusión a la exclusión, Santiago, DIBAM, Centro de Investigaciones Diego Barros Arana, 2003. En relación al papel de la ciudadanía en el proceso de formación estatal en América Latina véase Sábato, Hilda (coord.), Ciudadanía política y la formación de las naciones. Perspectivas históricas de América Latina, México, El Colegio de México, Fondo de Cultura Económica, Fideicomiso Historia de las Américas, 1999.

25. Estefane, Andrés, «Burócratas ambulantes. Movilidad y producción de conocimiento estadístico en Chile, 1860-1873», Revista Enfoques n. ${ }^{\circ}$ 10, Santiago, 2012, pp. 123-146.

26. Barría Traverso, Diego, La autonomía estatal y clase dominante en el siglo XIX chileno: la guerra civil de 1891, Proefschrift ter verkrijging van de graad van Doctor aan de Universiteit Leiden, Leiden, Universiteit Leiden, 2013. 
Los artículos que se proponen vienen a llenar un vacío en la discusión disciplinaria y contribuyen a establecer un diálogo entre las distintas escalas en las que se desarrolla dicho proceso (nacional-provincial). También favorecen la discusión con otras realidades latinoamericanas, cuanto más que la perspectiva regional se ha desarrollado con fuerza (el caso de la historiografía regional argentina es un ejemplo). ${ }^{27}$ Asimismo, es importante señalar que este dossier aportará a una reflexión sobre el Estado que en ningún caso está clausurada, como lo demuestra la renovada discusión sobre el régimen político constitucional que rige a Chile en el presente. La demanda de la sociedad civil en torno a una nueva constitución, el debate en torno al centralismo y la asignación centralizada de los recursos fiscales, y la representación política ligada a la organización político-administrativa son efectivamente ejemplos de la vigencia que tiene el estudio del proceso de formación estatal.

El artículo de Armando Cartes «De época maldita a epopeya liberal: una revisión historiográfica a la anarquía chilena (1823-1830)» realiza un análisis de cómo la historiografía ha abordado el período comprendido entre los años 1823 y 1830 . Teniendo en cuenta como los sesgos, tanto políticos como intelectuales, generados por los contextos de producción de los textos historiográficos influyeron en las interpretaciones que los historiadores realizaron sobre dicho período, el autor revisa el modo en que estas han oscilado desde calificarla como el momento germinal de instituciones y libertades públicas, hasta considerarla como un período de desgobierno y «anarquía».

Cabe destacar que, como conclusión de su análisis crítico, Cartes enfatiza en la necesidad de poner atención a los proyectos alternativos que estaban en juego en el período inicial de vida republicana. De esta manera, genera dos prevenciones importantes para el análisis del período estudiado. En primer lugar, sirve de advertencia contra la tendencia a la realización de narraciones con sesgos teleológicos que consideren el triunfo del orden centralista-autoritario del peluconismo como el resultado natural y necesario de los conflictos del período postindependentista. En segundo lugar, es un llamado a centrar la mirada en actores cuya importancia ha tendido a ser relegada a un rol secundario en las narraciones históricas, pese a la relevancia que tuvieron en su momento de actividad política. La necesidad de atender las ideas y proyectos de dichos actores, trascendiendo al énfasis en el análisis de sus intereses inmediatos, permite esclarecer los rumbos que tomaron los debates intelectuales y las disputas, tanto políticas como militares, del período en cuestión.

El texto de Cristóbal García-Huidobro «Tradición y revolución en la formación del Estado en Chile post independiente: las asambleas provinciales (1822-1830)» pone de relieve un tema historiográfico clave: la discusión sobre los elementos de continuidad y cambio en el período de la Independencia. En un estudio acucioso sobre el marco jurídi-

27. Cf. Bragoni, Beatriz y Eduardo Míguez, Un nuevo orden político..., cit.; Bragoni, Beatriz, Los hijos de la revolución. Familia, negocios y poder en Mendoza en el siglo XIX, Buenos Aires, Taurus, 1999; Barriera, Darío, Instituciones, Gobierno y Territorio. Rosario, de la capilla al municipio (1725-1930), Rosario, ISHIR CONICET, 2010; y Garavaglia, Juan Carlos, San Antonio de Areco, 1660-1880, Rosario, Prohistoria, 2009. 
co/teórico y la conformación y organización de las asambleas provinciales, el autor muestra que los conflictos y el clima de desorganización que dan origen al surgimiento de estas instituciones son indicadores de una transición paulatina entre el Antiguo Régimen colonial y el modelo revolucionario. El cambio de paradigma político entre la concepción pactista de la soberanía y la representación de las ideas revolucionarias en que la soberanía reside en una comunidad abstracta que conforma el Estado moderno no se da de la noche a la mañana. Así, el debate sobre la forma de Estado que se busca organizar se encuentra tensionado entre elementos tradicionales y modernos y entre las pretensiones centralistas de Santiago y las reivindicaciones locales del resto de las provincias.

Si miramos desde otro ángulo, el estudio de las asambleas provinciales permite abordar la cuestión de la tensión que existe entre las élites locales y el poder central; un resultado inherente a la construcción del monopolio legítimo de la violencia característico de la formación estatal. Las élites locales observan cómo en el transcurso de este proceso comienzan a perder sus antiguas prerrogativas en pro de las élites de la capital que controlan la incipiente institucionalidad y burocracia del Estado, y su respuesta, apelando a una larga tradición, es organizar las asambleas provinciales. En palabras de García-Huidobro estas instituciones serán un vehículo para la representación de las demandas locales y un polo de resistencia ante el avance centralizador de la capital. Las asambleas provinciales son así herederas de una tradición corporativa que tenía en los cabildos una clara expresión de autogobierno - y autodefensa—, y que se evidencia en la proveniencia de sus miembros, la mayoría antiguos cabildantes.

En el artículo «El Estado en la Provincia. La organización institucional y administrativa en el norte de Chile tras la independencia», Elvira López Taverne analiza la organización institucional y la conformación de una administración pública en un ámbito local del Chile postindependentista: en este caso, la Provincia de Coquimbo, correspondiente al norte chileno del período. La autora da cuenta de la precariedad de la presencia estatal en la zona. En el marco de una administración escasamente burocratizada, muchas de las autoridades subalternas eran «notables del pueblo o villa», actuando como «bisagras entre las demandas de la sociedad local y el Intendente provincial». En este contexto, se mantuvieron importantes continuidades respecto a las prácticas administrativas coloniales. De todas maneras, se hace patente cómo la vocación productiva de la región se relaciona directamente con su desarrollo institucional. Así, la administración y el gobierno de la provincia se articuló en torno a la minería y el comercio internacional. Con todo, quedan en evidencia las distintas intencionalidades subyacentes a las reformas administrativas que fueron aplicadas en la región. Esto se nota especialmente en el afán del orden pelucón de afianzar el control político de las provincias.

Por último, el artículo de Carlos Zúñiga «La fundación de la provincia de Talca y la división político-administrativa de 1826» permite abordar uno de los temas fundamentales del proceso de construcción estatal chileno en sus primeras décadas: la precariedad material e institucional. Siguiendo la vida política local de la ciudad y provincia de Talca (ubicada $260 \mathrm{~km}$ al sur de Santiago) en la primera década independiente, el autor se centra en el conflicto que generó la división político administrativa de 1826 y en las tensiones 
centro-provincia que derivaron de ella. Como ilustra el texto, la poca coordinación y capacidad del gobierno central para implimentar esta nueva división, ${ }^{28}$ permitió que la élite local desconociera la nueva legislación y mantuviera de facto una situación de rebeldía, pero sin sustraerse de participar en las instancias políticas a nivel nacional. Por otra parte, deja en claro que el objetivo de la comunidad local era una mayor cuota de representación y participación en la política local, que de hecho se logró al desconocer la nueva división y la nueva jerarquía administrativa.

Ahora bien, los argumentos con que se cuestiona la nueva organización evidencian el rol preponderante que se atribuye desde temprano a aspectos más concretos y materiales, como son la producción económica y la demografía local; los números parecen darle la razón a las autoridades locales que reivindican una posición independiente, o al menos no subordinada a la ciudad de Curicó, vecina y rival. El proyecto de formación estatal era factible en la medida en que fuera viable económicamente, y el texto muestra que los actores locales eran conscientes de ello.

De los artículos se desprende la coexistencia de ideas, proyectos e intereses divergentes en el proceso de construcción nacional y la permanencia de instituciones y prácticas heredadas del período colonial, en el marco de un escenario caracterizado por la precariedad material del incipiente Estado. En este sentido, la propuesta de este dossier es por tanto estudiar las tensiones, los desafíos, las contradicciones y los obstáculos (políticos, ideológicos y materiales) que comportó el proceso de formación estatal en Chile en la primera mitad del siglo XIX, en sus diversas formas y proyectos, a la vez que cuestionar la implementación de un modelo estatal fuertemente centralizado desde una nueva escala de observación: la regional.

\section{Bibliografía:}

Alberdi, Juan Bautista, Bases y puntos de partida para la organización política de la República de Argentina, [texto editado por Francisco Cruz], Buenos Aires, La cultura argentina, 1915.

Barría Traverso, Diego, La autonomía estatal y clase dominante en el siglo XIX chileno: la guerra civil de 1891, Proefschrift ter verkrijging van de graad van Doctor aan de Universiteit Leiden, Leiden, Universiteit Leiden, 2013.

Barriera, Darío, Instituciones, Gobierno y Territorio. Rosario, de la capilla al municipio (1725-1930), Rosario, ISHIR CONICET, 2010.

Bendix, Reinhard, Estado nacional y ciudadanía, Buenos Aires, Amorrortu Editores, 1974.

Blumenthal, Edward, El mito de la excepcionalidad chilena: un proyecto de construcción identitaria,

28. Sobre las dificultades que experimenta la implementación de políticas censales y levantamientos estadísticos véase Estefane, Andrés, «La institucionalización del sistema estadístico chileno: debates y problemas prácticos (1843-1851)», Estudios Sociales del Estado, vol. 2, n. ${ }^{\circ}$ 4, Buenos Aires, segundo semestre de 2016, pp. 35-73 y Estefane, Andrés, «Un alto en el camino para saber cuantos somos. Los censos de población y la construcción de lealtades nacionales. Chile, siglo XIX», Historia, n. ${ }^{\circ}$ 37, vol. I, Santiago, enero-junio de 2004, pp. 33-59. 
Tesis para optar al grado de Licenciado en Historia, Santiago, Instituto de Historia de la Pontificia Universidad Católica de Chile, 2004.

Bragoni, Beatriz y Eduardo Míguez (comps.), Un nuevo orden político. Provincias y Estado Nacional, 1852-1880, Buenos Aires, Editorial Biblos, 2010.

Bragoni, Beatríz, Los hijos de la revolución. Familia, negocios y poder en Mendoza en el siglo XIX, Buenos Aires, Taurus, 1999.

Bravo Lira, Bernardino, Historia de las instituciones políticas de Chile e Hispanoamérica, Santiago, Editorial Andrés Bello, 1986.

Carmagnani, Marcello (comp.), Federalismos latinoamericanos, México-Buenos Aires, Fondo de Cultura Económica, 1994.

Cartes Montory, Armando, «Un gobierno de los pueblos...» Relaciones provinciales en la Independencia de Chile, Valparaíso, Ediciones Universitarias de Valparaíso, 2014.

-, Concepción contra Chile. Consensos y tensiones regionales en la Patria Vieja (1808-1811), Santiago, Centro de Estudios Bicentenario, 2010.

Collier, Simon, Chile. La construcción de una república, 1830-1865, Santiago, Ediciones Universidad Católica de Chile, 2008.

Estefane, Andrés, «Burócratas ambulantes. Movilidad y producción de conocimiento estadístico en Chile, 1860-1873», Revista Enfoques n. ${ }^{\circ}$ 10, Santiago, 2012, pp. 123-146.

—, «La institucionalización del sistema estadístico chileno: debates y problemas prácticos (18431851)», Estudios Sociales del Estado, vol. 2, n. ${ }^{\circ} 4$, Buenos Aires, segundo semestre de 2016, pp. 35-73.

-, «Un alto en el camino para saber cuantos somos. Los censos de población y la construcción de lealtades nacionales. Chile, siglo XIX», Historia, n. ${ }^{\circ} 37$, vol. 1, Santiago, enero-junio de 2004 , pp. 33-59.

Eyzaguirre, Jaime, Historia de las instituciones politicas y sociales de Chile, Santiago, Editorial Universitaria, 1967.

Fernández Abara, Joaquín, Regionalismo, liberalismo y rebelión. Copiapó en la guerra civil de 1859, Santiago, RIL Editores - Escuela de Historia de la Universidad Finis Terrae, 2016.

Garavaglia, Juan Carlos, San Antonio de Areco, 1660-1880, Rosario, Prohistoria, 2009.

Gazmuri Riveros, Cristián, La Historiografía Chilena (1842-1970), tomos I y II, Santiago, TaurusCentro de Investigaciones Diego Barros Arana, 2006-2009.

Góngora, Mario, Ensayo histórico sobre la noción de Estado en Chile en los siglos XIX y XX, Santiago, La Ciudad, 1981.

Guerrero Orozco, Omar, Las raíces borbónicas del Estado Mexicano, México D.F., Universidad Nacional Autónoma de México, 1994.

Halperín Donghi, Tulio, Historia contemporánea de América Latina, Madrid, Alianza Editorial, 1972.

Illanes, María Angélica, Chile Des-centrado. Formación socio-cultural republicana y transición capitalista (1810-1910), Santiago, Lom Ediciones, 2003.

Jocelyn-Holt, Alfredo, El peso de la noche: nuestra frágil fortaleza histórica, Buenos Aires, Editorial Planeta, 1997.

—, La independencia de Chile. Tradición, modernización y mito, Madrid, Mapfre, 1992.

Kocka, Jurgen y Heinz-Gerhard Haupt, «Comparison and Beyond. Tradition, Scope, and Perspectives of Comparative History», en Kocka, Jurgen y Heinz-Gerhard Haupt (eds), Comparative and Transnational History. Central European Approaches and New Perspectives, New YorkOxford, Berghahn Books, 2012, pp. 1-32. 
López Taverne, Elvira, El proceso de construcción estatal en Chile. Hacienda Pública y burocracia (1817-1860), Santiago, Centro de Investigaciones Diego Barros Arana, 2013.

Mann, Michael, Las fuentes del poder social. Tomo II. El desarrollo de las clases y los estados nacionales, 1760-1914, Madrid, Alianza Editorial, 1991.

Pinto, Jorge, La formación del Estado y la nación y el pueblo Mapuche. De la inclusión a la exclusión, Santiago, DIBAM, Centro de Investigaciones Diego Barros Arana, 2003.

Pinto, Julio y Verónica Valdivia, ¿Chilenos todos? La construcción social de la nación (1810-1840), Santiago, Lom Ediciones, 2009.

Pinto, Julio, «¿La tendencia de la masa al reposo? El régimen portaliano enfrenta al mundo plebeyo, 1830-1851», Historia, n. ${ }^{\circ}$ 44, vol. II, Santiago, julio-diciembre 2011, pp. 401-442.

Pro Ruiz, Juan, «Considering the State from the Perspective of Bureaucracy: Lessons from the Latin American Sattelzeit», en Garavaglia, Juan Carlos y Juan Pro Ruiz (eds.), Latin American Bureaucracy and the State Building Process (1780-1860), Newcastel upon Tyne, Cambridge Scholars Publishing, 2013, pp. 1-23.

Rabinovich, Alejandro, «La militarización del Río de la Plata, 1810-1820: Elementos cuantitativos y conceptuales para un análisis», Boletín del Instituto de Historia Argentina y Americana Dr. Emilio Ravignani, n. ${ }^{\circ}$ 37, Buenos Aires, 2012, pp. 11-42.

-, «De la historia militar a la historia de la guerra. Aportes y propuestas para el estudio de la guerra en los márgenes», Corpus. Archivos virtuales de la alteridad americana [en línea], vol. 5, n. ${ }^{\circ}$ 1, Mendoza, 2015, Publicado el 29 junio 2015, consultado el 11 julio 2018. URL: <http:// journals.openedition.org/corpusarchivos/1397>.

Sábato, Hilda (coord.), Ciudadanía política y la formación de las naciones. perspectivas históricas de América Latina, México, El Colegio de México, Fondo de Cultura Económica, Fideicomiso Historia de las Américas, 1999.

Sagredo, Rafael, «Élites chilenas del siglo XIX. Historiografía», en Cuadernos de Historia, n. ${ }^{\circ}$ 16, Santiago, diciembre de 1996.

Salazar, Gabriel y Julio Pinto, Historia contemporánea de Chile, Santiago, Lom Ediciones, vol. I, 1999.

Salazar, Gabriel, Construcción de Estado en Chile (1800-1837). Democracia de los «pueblos». Militarismo ciudadano: Golpismo oligárquico, Santiago, Editorial Sudamericana, 2006.

Soifer, Hillel David, State Building in Latin América, New York, Cambridge University Press, 2015.

Valenzuela, J. Samuel, «Hacia la formación de instituciones democráticas: Prácticas electorales en Chile durante el siglo XIX», Estudios Públicos, n. ${ }^{\circ}$ 58, Santiago, 1995.

Weber, Max, Economía y Sociedad, México, Fondo de Cultura Económica, 1964. 